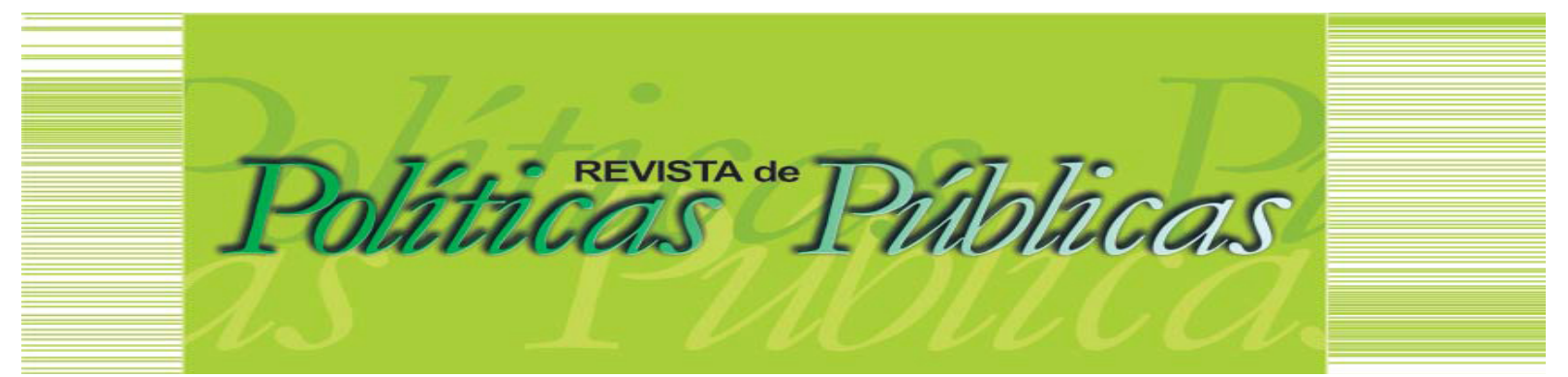

\title{
CORPOS NEGROS EXPOSTOS EM UMA PRAÇA DE ALIMENTAÇÃO DE UM SHOPPING
}

\begin{abstract}
Resumo:
O trabalho faz uma análise sobre um episódio ocorrido em novembro de 2013, cujo palco foi um shopping da capital do estado do Espírito Santo. Coloca em questão que, tal fato, pode ser compreendido como uma ação confirmativa da existência de preconceito e racismo institucional no Brasil, visto que dezenas de jovens foram tratados como cidadãos sem direitos por agentes da Polícia Militar, mesmo depois da constatação da inexistência de atos ilícitos praticados pelos jovens. Ressalta, ainda, que os frequentadores "usuais" do shopping também reconheceram como ilegítima a presença de jovens pretos, pobres e moradores de periferias, em um ambiente comercial localizado em uma área nobre da capital. Pesquisas documentais e bibliográficas formaram as principais fontes e subsídios para reflexões, afirmações e conclusões deste trabalho.
\end{abstract}

Palavras Chaves: Racismo Institucional. Preconceito. Configurações de Poder.

\section{BLACK BODIES EXPOSED IN A SHOPPING FOOD PLAZA}

\begin{abstract}
:
In November 2013, a shopping mall in the state capital of Espirito Santo was the scene of an episode that can be understood as a confirmation action of the existence of institutional prejudice and racism in Brazil. Dozens of young people were treated as citizens without rights by agents of the Military Police, even after the finding of the inexistence of unlawful acts practiced by young people. The "usual" shoppers also recognized as illegitimate the presence of black, poor and suburban residents in a commercial environment located in a prime area of the capital. Documentary and bibliographical research formed the main sources and subsidies for reflections, affirmations and conclusions of this work.
\end{abstract}

Keywords: Institutional Racism. Prejudice. Power Settings.

Artigo recebido em: 17/01/2019 Aprovado em: 22/04/2019.

DOI: http://dx.doi.org/10.18764/2178-2865.v23n1p97-114

\footnotetext{
${ }^{1} 1$ Bacharel em Ciências Sociais. Mestre em Políticas Públicas e Desenvolvimento Local pela Escola Superior de Ciências da Santa Casa de Misericórdia de Vitória (EMESCAM); Pós Graduado em Segurança Pública (UFES). Endereço: Práxis Vivere - Sociologia Contemporânea - AV BH, 1020, Nova Carapina I, Serra - ES. CEP: 29.170-038. E-mail: claudiosociologo@gmail.com

${ }^{2}$ Filósofo. Doutor em Serviço Social pela Universidade Estadual do Rio de Janeiro (UERJ). Coordenador do Mestrado em Políticas Públicas e Desenvolvimento Local e Professor da EMESCAM. Endereço: Av. Nossa Sra. da Penha, 2190 Santa Luzia, Vitória - ES. CEP: 2945402.
} 


\section{INTRODUÇÃO}

O objeto do trabalho é um estudo de caso que teve como instrumentos para sua realização, pesquisa bibliográfica e análise de mídias impressas e digitais, objetivando evitar que um evento ocorrido no dia 30 de novembro de 2013, na cidade de Vitória capital do estado do Espírito Santo, que alcançou repercussão nacional, seja tratado como uma casualidade, visto que sua singularidade o permite ser considerado, percebido e contextualizado como uma ação de preconceito e racismo institucional.

Semelhante a outras ocorrências que sugerem a prática de racismo, desnudando a existência de preconceito de cor no país, o referido episódio é um convite a um aprofundamento científico, visto que corriqueiramente fatos parecidos não recebem atenção, ou mesmo, são reduzidos a casualidades, permitindo que sejam tratados nos limites do senso comum.

Um shopping localizado na cidade de Vitória, capital do estado do Espírito Santo, foi o cenário de um acontecimento envolvendo jovens, em sua maioria negros e moradores de periferia, a Polícia Militar e outros atores sociais como: lojistas, profissionais da imprensa e frequentadores em geral do referido estabelecimento comercial de livre acesso público.

O texto narra o episódio, analisa os discursos e manifestações de autoridades civis e militares, comerciantes e profissionais da imprensa, correlaciona com obras teóricas sobre racismo e configuração de poder, apresentando conclusões que permitem refletir e dialogar em oposição as teses da não existência de racismo e preconceitos no Brasil.

\section{JOVENS EM FUGA CAPTURADOS PELO PRECONCEITO}

A Realização de uma festa por jovens e adolescentes, convocada por uma rede social da internet e denominada "[...] confraternização entre amigos do Facebook com 0 intuito de conhecer novas pessoas." (BOSSATO, 2013, p. 14). Tornou-se notícia em diversos instrumentos da imprensa formal e viralizou ${ }^{1}$ nas redes sociais, devido uma confusão causada dentro de um shopping da capital do ES, no dia 30 de Novembro de 2013.

A festa que era realizada em uma rua do bairro da Enseada do Suá, área nobre da cidade de Vitória, e culminou na entrada de aproximadamente 400 jovens em um shopping tradicional da capital, após uma confusão causada com a chegada da Polícia Militar ao local, pois os jovens entraram correndo no referido estabelecimento comercial de livre acesso ao público, causando confusão, conforme narrativa encontrada em um jornal diário capixaba.

Pânico e correria em shopping: Um grupo de aproximadamente 400 pessoas causou confusão ao entrar correndo no Shopping Vitória por volta das 18 horas na tarde de ontem. Eles entraram no local após confusão em evento que era realizado do lado de fora após a chegada da Polícia Militar. (BOSSATO, 2013, p.14). 
Outro periódico capixaba apresentou a seguinte narrativa para o fato:

Correria e perseguição policial em shopping: Jovens correram para o local, após abordagem em baile funk: Uma perseguição policial causou pânico entre funcionários e clientes no Shopping Vitória, na Enseada do Suá, no início da noite de ontem. Pessoas procuravam segurança no interior das lojas, que ficaram fechadas por quase uma hora (MIRANDA, 2013a, p. 14).

O episódio ganhou proporções nacionais e o caso foi destaque no blog Negro Belchior, da Revista de circulação nacional, Carta Capital, em sua versão online, onde Douglas Belchior, professor formado em História na PUC/SP2 ${ }^{2}$, educador nos cursinhos comunitários da Uneafro-Brasili ${ }^{3}$ e militante do movimento negro em São Paulo apresentou a seguinte narrativa:

Shopping Vitória: corpos negros no lugar errado: Sábado, 30 de novembro, fim de tarde. Várias viaturas da Polícia Militar, Rotam e Batalhão de Missões Especiais cercaram o Shopping Vitória, na Enseada do Suá, no Espírito Santo. Missão: proteger lojistas e consumidores ameaçados por uma gente preta, pobre e funkeira que, "soube-se depois", não ocuparam o shopping para consumir ou saquear, mas para se proteger da violência da tropa da PM que acabara de encerrar a força o baile Funk que acontecia no Pier ao lado (BELCHIOR, 2013, p. 1).

As narrativas apresentadas mesmo que com algumas diferenças permitem observar que a presença da Polícia Militar foi à mola propulsora que direcionou os participantes do evento em direção ao shopping, pois apresentam três fatos diretamente ligados com a ação policial: confusão após a chegada da Polícia Militar; perseguição policial e violência da tropa da PM.

Os jovens que estavam aparentemente se divertindo, pois nenhuma das narrativas informam sobre a ocorrência de fatos que os coloquem em condição de criminosos, mas mesmo assim são apontados como os responsáveis por tumulto, correria e situação de pânico no interior do shopping. Contudo, segundo as narrativas dos periódicos, somente após a chegada da Polícia Militar no evento, iniciou-se a ocupação do estabelecimento comercial de livre acesso público, causando a narrada confusão.

Os motivos que levaram a Polícia Militar até o local e as motivações para intervenção no evento, são fundamentais para 0 apontamento de responsabilidades sobre as causas originárias da chamada confusão no interior do shopping. Assim, os argumentos da Polícia Militar e da Secretaria de Estado Segurança Pública e Defesa Social do estado do Espírito Santo sobre o tema, são instrumentos importantes para compreensão do ocorrido.

Em um jornal online o secretário de Segurança Pública e Defesa Social na época, deu a seguinte declaração para explicar a ação da Polícia Militar:

Deslocamos os recursos da Policia Militar para o patrulhamento de um evento de dança de funk, pois havia o aglomerado de 400 pessoas no local. Os militares deram início a algumas abordagens quando um estampido foi ouvido (provavelmente o barulho de um escapamento de moto) e algumas pessoas confundiram com um disparo de arma de fogo. Diversos elementos correram para dentro do shopping, onde também foi necessária a ação da polícia. (FOLHA VITÓRIA, 2013, p. 1). 
Fica explicito na declaração do secretário de segurança, que a Polícia Militar se deslocou para o local sem que houvesse denúncia de crime, e que a presença de 400 pessoas no evento denominado pelo secretário de: um evento de dança de funk, foi o motivo que levou os policiais até o local, bem como a justificativa para que os policiais iniciassem abordagens a alguns participantes, ou seja, confirma-se a não existência de nenhuma ocorrência de ilícito, pois se reunir para ouvir música, não se caracteriza crime. Afirma ainda o secretário que dentro do shopping houve necessidade de ação policial, mesmo sem explicar qual foi à necessidade de ação policial fora do shopping.

O secretário também demonstra em sua fala que os jovens entraram no shopping em uma ação de fuga dos agentes da Polícia Militar, pois sem apresentar o motivo que levou a Polícia Militar até 0 evento, bem como as razões para que fossem realizadas abordagens aos presentes, o secretário de segurança pública e defesa social, apresentou uma suposição para explicar o início do que ele chamou de tumulto, pois de acordo com o secretário, o barulho de uma bombinha ${ }^{4}$ pode ter iniciado a denominada confusão (BOSSATO, 2013; CARVALHO; HEMERLY, 2013, p. 11).

Se é fato que a debandada dos jovens em direção ao shopping na busca de abrigo e segurança pode ter sido fruto de um engano em um momento de tensão, também é fato que 0 secretário de segurança do estado não compreendeu como equívoco o envio de uma tropa especializada da Polícia Militar para encerrar uma festa, ou manifestação cultural pacífica de um grupo de jovens.

A versão passada por um interlocutor da Polícia Militar apresenta semelhanças com as narrativas do secretário de segurança, mas trazem novos elementos:

\footnotetext{
O corre-corre do último sábado, na Enseada do Suá, em Vitória, foi provocado pelo barulho de canos da descarga de motos que faziam manobras na rua Marília de Rezende Scapin Coutinho, enquanto acontecia uma festa, atrás do Shopping Vitória. A afirmação é do comandante interino do Batalhão e Missões Especiais (BME), major Geovanio Silva Ribeiro. "Embora a Polícia Militar não tenha sido comunicada sobre o evento, diante da aglomeração no local, mais de 400 pessoas, o comando da PM designou que militares do $1^{\circ}$ Batalhão ficassem na região. O BME foi acionado às 18 horas, para desobstruir a via, que tinha sido tomada pelos participantes da festa. Não tivemos nenhum problema para isso, não foi feito nenhum disparo. Apenas, posicionamos a tropa", garantiu (HEMERLY, 2013, p. 20).
}

Os relatos do oficial da Polícia mostram que os policiais do $1^{\circ}$ Batalhão da Polícia Militar, mesmo sem terem sido informados da festa, estavam no local acompanhado os acontecimentos, mas com exceção do número de pessoas e uma possível interrupção de uma rua, nada de ilícito foi narrado, bem como que os policiais do Batalhão de Missões Especiais da Polícia Militar (BME) ${ }^{5}$, fora acionado com um único objetivo: desobstruir a via, ou seja, o BME foi acionado para ir até o local já possuindo 0 conhecimento que não se tratava de um fato de ocorrência de crime, mas sim uma simples obstrução de rua, permitindo os seguintes questionamentos: 
- Por que estes militares não acionaram a Guarda Municipal de Vitória ${ }^{6}$ que é a responsável pelo trânsito na cidade?

- Por que chamar para ao local o batalhão de elite da Polícia Militar - o Batalhão de Missões Especiais, sem antes tentar um diálogo com os participantes do evento, buscando desobstruir a rua por eles ocupada?

As informações do oficial da Polícia Militar não falam em abordagem aos participantes, mas sim de posicionamento da tropa do $\mathrm{BME}$, o que pressupõe que esta tropa estava pronta para usar a força para desobstruir a rua ocupada, condição que pode ter contribuído para que o suposto barulho causado por uma bombinha ou pelo escapamento de uma moto ${ }^{7}$ tenha sido percebido pelos participantes do evento como um ataque, sem motivos aparente ao grupo. Fato que explicaria a tentativa de busca de proteção dos jovens no interior do shopping.

As informações trazidas pelos agentes públicos favorecem a construção de ideias sobre a discriminação com a qual os jovens moradores de periferias formados em sua maioria por pretos e pardos, em especial aqueles que externam seus gostos por estilos musicais desaprovados por setores da sociedade, são relacionados e estereotipados como marginais prontos para delinquir.

\footnotetext{
Em termos sociológicos, a discriminação geralmente se refere à diferenciação injusta $\mathrm{e}$ arbitrária, que tem na sua base a crença de que os indivíduos que pertencem a determinadas categorias ou grupos - como social, racial, político, religioso e sexual, entre outros - têm maior probabilidade de possuir características indesejáveis. 0 racismo é um caso particular de discriminação em que o indivíduo, por sua cor da pele (ou raça), pode sofrer tratamentos diferenciados, no sentido de ter bloqueadas oportunidades sociais e econômicas, ou simplesmente de ser alvo de segregação. (CERQUEIRA; MOURA, 2013, p. 2).
}

O objetivo principal dos jovens ao buscarem refúgio no interior do shopping era não ser vitimados por uma possível agressão injusta por parte da Polícia Militar, que sem dialogar, como ficou demonstrado nas declarações públicas dos agentes responsáveis pela segurança pública, enviara para o ambiente onde os jovens realizavam um evento de dança de funk, o BME, seu instrumento de maior poder ofensivo, em treinamento, técnica e equipamentos, que em teoria deveria ser empregado somente onde não existisse nenhuma possibilidade de resolução por parte das unidades regulares da Polícia Militar.

A ação da Polícia Militar dentro do shopping merece uma atenção ainda maior, pois baseado nas falas das autoridades, já demonstradas anteriormente, que não apontam atos ilícitos cometidos pelos jovens até o momento do ingresso do grupo no interior do referido espaço comercial de livre acesso ao público, compreender-se-ia que a Polícia Militar não agisse como se estes jovens fossem suspeitos, mas o inverso disso aconteceu. 
Ao entrarem no shopping os jovens foram perseguidos pela Polícia Militar, fato que causou enorme tumulto entre as pessoas que já se encontravam no interior do shopping. Muitas lojas foram fechadas pelos próprios seguranças do complexo comercial e funcionários de lojas, enquanto pessoas corriam e procuravam abrigo no interior dos estabelecimentos comerciais, sem mesmo saber o que estava acontecendo. (BOSSATO, 2013).

A Polícia Militar ocupou o shopping e iniciou um procedimento de abordagem seletiva e arbitrária aos jovens que estavam presentes, que mesmo após terem sido revistados e constatado que não haviam cometido nenhum crime ou ato infracional, foram conduzidos à praça de alimentação do shopping, obrigados a retirarem as camisas e a sentarem-se no chão com as mãos entrelaçadas na nuca, rodeados de policiais e sob a mira de armas (BOSSATO, 2013).

A ação terminou com os jovens sendo enfileirados e, obrigados a colocar as mãos nos ombros do jovem que estava a sua frente, sendo todos coagidos pela Polícia Militar a se retirarem compulsoriamente de um ambiente de livre acesso público, mesmo depois das revistas e demais procedimentos policiais constatarem que nenhum dos jovens abordados havia cometido crimes ou atos infracionais.

A ação policial foi acompanhada por inúmeros frequentadores do shopping, que fotografavam e filmavam toda a cena, abastecendo em tempo real diversas redes sócias da internet, estes frequentadores, que em momento algum foram vítimas de suspeita por parte dos policias militares, demonstravam apoio à ação policial por meio de aplausos para forma com que os policiais agiam e vaias para os jovens abordados e subjugados, quando estes foram obrigados a deixar 0 espaço comercial. Era visível a separação entre os que se acreditam frequentadores e aqueles que foram arbitrados como invasores. Como narra um profissional da imprensa que foi ao local fazer a cobertura jornalística do fato, ao descrever a cena e emitir sua opinião sobre o acontecimento e suas experiências de vida.

As pessoas vaiaram, xingaram e aplaudiram os policiais no shopping, mas isso não me surpreende. Por ser negro, vivo a discriminação quase que diariamente em Vitória. Talvez, minha vida seria mais fácil, ou eu seria mais aceito se ouvisse meus amigos, colegas, parentes e conhecidos e fizesse minha barba (que é horrível e eu adoro), ou se me vestisse melhor. Não é questão de orgulho, eu sou assim e pronto. Vivemos num tempo em que 0 medo predomina, mas o medo e a burrice (apesar de muitas vezes caminharem juntos) não são a mesma coisa. (MIRANDA, 2013b, p.10).

Há impressão que a Polícia Militar protagonizou um apartamento entre aqueles que discricionariamente, os comandantes da operação avaliaram não fazer parte daquele ambiente, por conseguinte, foram julgados culpados por todos os transtornos que estavam sendo causados. Isso ficou evidenciado no momento em que as pessoas foram reunidas no chão da praça de alimentação, como indivíduos sem direitos. Fato que chamou a atenção do Conselho Estadual de Direitos Humanos 


\section{CORPOS NEGROS EXPOSTOS EM UMA PRAÇA DE ALIMENTAÇÃO DE UM SHOPPING}

$(C E D H)^{8}$, que repudiou em nota pública a ação policial no shopping, denunciando o caso como explicito ato de preconceito:

Para o colegiado, a violência desproporcional e os procedimentos humilhantes aos quais foram submetidos aqueles jovens basearam-se exclusivamente no preconceito e na tendência de marginalização e criminalização de qualquer manifestação social e cultural que não tenha sua gênese dentro dos parâmetros estéticos legitimados pelas convenções elitistas vigentes. $\mathrm{O} C E D H$ salienta que o funk é um movimento cultural autêntico, expressão da juventude negra das periferias das cidades. $O$ conselho também aponta que as imagens divulgadas nos jornais mostram que jovens foram publicamente submetidos a tratamento degradante e humilhante, colocados sentados sem camisa no pátio da praça de alimentação com as cabeças baixas e as mãos cruzadas sobre a nuca e, após, conduzidos em fila indiana para fora do shopping, em procedimento similar ao que ocorre no interior dos presídios capixabas. (FRANCEZ, 2013, p. 1).

Perguntado sobre a ação dos policiais o secretário de segurança pública e defesa social deu uma declaração confirmando que as pessoas foram escolhidas dentro de uma visão préestabelecida de quem é ou não suspeito dentro de um critério subjetivo, e que não cabe questionamentos sobre estes critérios que não são explicados pelo secretário, visto que ao invés de explicar o que leva um policial a identificar uma pessoa como suspeita, ele simplesmente afirmou que isso é uma atitude legal e o papel da sociedade é entender, mesmo que não tenha uma explicação plausível para os motivos que levem à abordagem.

Sobre as abordagens dentro e fora do shopping, André Garcia disse que foram realizadas dentro da normalidade. "Quando existe uma atitude suspeita, a abordagem é uma ação normal. A polícia está autorizada a fazer isso. A população tem que entender", disse 0 secretário, afirmando que o critério para uma abordagem depende das circunstâncias, perfil das pessoas e quais queixas são apresentadas. (MIRANDA, 2013b, p. 10).

Ao descrever como normal a ação da polícia em relação aos jovens no interior do shopping, o secretário também expõe que pode acreditar ser normal permitir que a polícia haja com pré-conceito e discriminação, principalmente ao se referir ao perfil das pessoas abordadas, visto que com essa afirmação o secretário demonstra aceitar ser possível que uma pessoa possa ser considerada suspeita de um crime, ou mesmo considerada uma potência criminosa apenas por sua aparência.

Os critérios para as abordagens da polícia aos jovens no interior do shopping parecem não ter encontrado apoio nos argumentos apresentados pelas autoridades ao discorrerem sobre a circunstância da ocorrência do fato, visto que já foi demonstrado que a polícia não possuía informações sobre prática criminosa dos jovens no exterior do shopping, também não havia queixas de práticas criminosas no interior do shopping como será demonstrado a seguir.

A ocorrência de um arrastão $0^{9}$ foi descartada pela administração do shopping, que também afirmou que não houve nenhum relato de furto no interior do complexo comercial, bem como não foi registrado nenhuma queixa sobre danos físicos às lojas. 
O Shopping Vitória descartou a ocorrência de um arrastão no estabelecimento e afirmou que nenhuma loja foi roubada ou danificada durante o tumulto. Uma lojista, que pediu para não ser identificada, estava perto da praça de alimentação e presenciou a abordagem dos policiais. "A maioria dos jovens abordados era menor de idade. Vi um policial dando um soco, de baixo para cima, em um garoto" (MIRANDA, 2013b, p. 10).

Os jovens foram submetidos à busca pessoal ${ }^{10}$, mesmo que não tenha ocorrido roubo, furto ou depredação de patrimônio durante o denominado tumulto, bem como houve relato de violência policial, ações que podem ser questionadas em relação ao que diz a lei sobre as condições para realização de abordagem policial que venha atender a figura jurídica denominada Fundada Suspeita, como poderá ser observado no comentário do jurista Guilherme de Souza Nucci (2007), sobre 0 art. 244 do Código de Processo Penal (CPP) ${ }^{11}$, que trata Busca Pessoal.

Fundada suspeita: é requisito essencial e indispensável para a realização da busca pessoal, consistente na revista do indivíduo. Suspeita é uma desconfiança ou suposição, algo intuitivo e frágil, por natureza, razão pela qual a norma exige fundada suspeita, que é mais concreto e seguro. Assim, quando um policial desconfiar de alguém, não poderá valer-se, unicamente, de sua experiência ou pressentimento, necessitando, ainda, de algo mais palpável, como a denúncia feita por terceiro de que a pessoa porta o instrumento usado para o cometimento do delito, bem como pode ele mesmo visualizar uma saliência sob a blusa do sujeito, dando nítida impressão de se tratar de um revólver. Enfim, torna-se impossível e impróprio enumerar todas as possibilidades autorizadoras de uma busca, mas continua sendo curial destacar que a autoridade encarregada da investigação ou seus agentes podem - e devem revistar pessoas em busca de armas, instrumentos do crime, objetos necessários à prova do fato delituoso, elementos de convicção, entre outros, agindo escrupulosa e fundamentadamente (NUCCl, 2007, p. 502).

Há estudos que apontam a existência de uma ação seletiva por parte dos policiais no momento de definirem quais jovens devem ser abordados e que o fator modo de se vestir e cor de pele estão entre as razões da seleção.

Pesquisas no Rio de Janeiro evidenciam esse dado do nosso estudo, que destaca como um
dos aspectos que mais chamam a atenção dos PMs em relação à característica do jovem a
moda e a aparência. A população pesquisada por Silvia Ramos e Leonarda Musumeci (2005,
p. 209) menciona que as abordagens policiais são, de um modo geral, seletivas e
discriminatórias. Dos pesquisados, $60 \%$ consideravam que a polícia selecionava para
abordagem com base na aparência física, incluindo nesse dado a cor da pele e o modo de
vestir (SOUSA; GOMES, 2011, p. 536).

A seletividade dos policiais nas práticas de abordagens daqueles indivíduos considerados como potenciais criminosos ou suspeitos de práticas de delitos está diretamente ligada a um cenário social que posiciona o negro em uma condição de exclusão socioeconômica, pois uma leitura baseada no senso comum propicia uma compreensão turva da realidade da população negra, visto que ao não considerar as condições de formação histórica do Brasil, em especial os entraves sociais, políticos, econômicos e até culturais, que não permitiram o desenvolvimento igualitário da população de negros e brancos no país, não será possível entender quais as razões que levam os negros a serem pinçados pelos agentes policiais, em meio a diversos sujeitos no momento das abordagens.

Diferentes clivagens contribuem para este cenário social: situação ocupacional, carência de profissionalização, baixa escolaridade, gênero, origem regional, idade e, acima de tudo, cor. 


\section{CORPOS NEGROS EXPOSTOS EM UMA PRAÇA DE ALIMENTAÇÃO DE UM SHOPPING}

Negros -- homens e mulheres, adultos e crianças -- encontram-se situados nos degraus mais inferiores das hierarquias sociais na sociedade brasileira, como vêm demonstrando inúmeros estudos e pesquisas. A exclusão social é reforçada pelo preconceito e pela estigmatização. No senso comum, cidadãos negros são percebidos como potenciais perturbadores da ordem social, apesar da existência de estudos questionando a suposta maior contribuição dos negros para a criminalidade Sellin (1928 apud PIRES; LANDREVILLE, 1985). Não obstante, se 0 crime não é privilégio da população negra, a punição parece sê-lo. (ADORNO, 1996, p. 283-284).

Dissertação apresentada por um oficial da PM do estado de São Paulo em 2009, na Universidade Federal de São Carlos, intitulada A Relação da Polícia Militar Paulista com a Comunidade Negra e o Respeito à Dignidade Humana: a Questão da Abordagem Policial - demonstra que os policiais consideram tanto as questões econômicas quanto étnico raciais na definição da pessoa a ser abordada, bem como que o policial de negro não se reconhece como negro e acredita não agir com racismo, mesmo que deixe evidenciado considerar o fator cor na escolha do suspeito. As afirmações deste parágrafo ficam explicitas na apresentação das falas dos indivíduos participantes da pesquisa, policiais e não policiais.

0 policial negro não se vê negro: Esta postura atinge também o policial negro, que não se sente negro ao realizar abordagem em negros, há um encobrimento de sua identidade racial na realização dessa prática social, porque a polícia não ensina nada sobre ser negro. Ao contrário, fazem a gente esquecer isso quando querem mostrar que a polícia não discrimina. A gente faz tudo para não ser o preto da turma, do pelotão, da companhia. Com este encobrimento, o policial negro não se vê no outro, não consegue colocar-se no lugar do outro e agir de forma diferente na abordagem: sou preto, mas não admito o uso da cor, da raça, para fazer coisa errada. "Neguinho" tem que ser melhor que o branco porque senão vai se dar mal na vida. Mas eu não quero nem saber se é preto ou branco; se é "pra dar mão na cabeça" é todo mundo igual. (RIBEIRO, 2009, p. 85, grifos do autor).

0 negro é escolhido mesmo estando correto: 0 abordado sabe que a escolha da pessoa a ser abordada pelo policial recai sobre o negro: [...] o fato de eu ser negro e estar vestido ao estilo hip-hop foi decisivo para aquela situação [...], e isto é histórico, pois em São Paulo, no começo do séc. XX, na Praça da Sé, local onde jovens negros se reuniam para depois ir a bailes, era absolutamente comum ser abordado de forma desrespeitosa pela polícia. A questão do perfil racial, assim, é algo que está presente na formação da sociedade brasileira, e o preconceito se situa além da racionalidade, por isso, não basta a informação, ela é absolutamente fundamental, mas não alcança a plenitude do problema, pois as pessoas não estão preparadas para conviver com negros. O negro é escolhido mesmo estando correto, pois nas situações em que há flagrante desrespeito à lei, praticado por branco, estando o negro perto, e em situação de legalidade, ele será abordado: [...] escolhido para ser abordado dentre outros 3 motociclistas com garupas, não-negros, sendo dois sem capacete e uma moto com placa ilegível, em flagrante estado de irregularidade dos motociclistas liberados. Em algumas localidades, é controlado o fluxo de pessoas nas ruas, às vezes atemorizando-as. Em São Carlos, por exemplo, não se pode ficar na rua depois das dez horas da noite; isso para alguns grupos sociais, especialmente os negros da periferia. (RIBEIRO, 2009, p. 86-87, grifos do autor).

Os argumentos apresentados são obstáculos para impedir tentativas de distanciamentos da ação dos policiais no shopping com a discussão da existência de preconceito racial e práticas de racismo na sociedade brasileira, em especial por parte de instituições que tem como função prestar serviço com igualdade para todos os cidadãos e cidadãs, independentemente de suas diferenças, mas 
também não pode ser utilizado como instrumento determinante para condicionar e rotular definitivamente os agentes envolvidos.

Assim, não é possível direcionar a pecha de racista ao secretário de estado, nem tampouco aos policiais (em especial os responsáveis em comando) que participaram das abordagens no shopping, pois suas ações, reações e apresentação de justificativas vão muito além das simples concepções pessoais em relação às múltiplas situações contidas nos fatos. Há uma gama de condicionantes históricas, econômicas, sociais, culturais e políticas que propiciaram ao longo do tempo e propiciam na atualidade a existência de fatores objetivos e subjetivos que influenciam na formação da consciência dos agentes relacionados, bem como não é possível formar um juízo que direcione para isenção ou inocência destes agentes, pois a responsabilidade de um servidor público, que tem como obrigação direta servir a sociedade sem diferenciar os indivíduos, a não ser nos casos previstos em lei, obriga os agentes citados, tratar a todos com igualdade plena, independentemente de suas concepções pessoais, visto que ninguém deveria estar acima da lei.

Os jovens depois de abordados e devidamente revistados, não foram liberados pelos agentes policiais, mesmo tendo sido constatado que eles não haviam cometido nenhum ato ilícito. Pois não foi uma ação delituosa que provocou a ação da Polícia Militar e o chamado tumulto, mas sim a presença naquele espaço de um grupo indesejado, aos olhos dos frequentadores usuais e dos policiais.

Vale ainda frisar na integra uma das declarações dada pelo advogado André Moreira (2013, p. 37):

\begin{abstract}
O curioso é que o gatilho do medo social que causou a reação instantânea de ódio contra os funkeiros nunca foi acionado diante da multidão de jovens, em sua maioria brancos, que invadiam as vias públicas, tomando as avenidas e isolando bairros como Jardim Camburi e Mata da Praia para fazer seu carnaval particular. [...] A cena correu o Brasil. Jovens negros e brancos pobres, os pretos e quase pretos de que fala a música, sentados enfileirados no chão do Shopping Vitória, com as mãos na cabeça, sob a mira da Polícia Militar e o aplauso dos consumidores, numa repetição daquilo que o movimento negro e os ativistas de direitos humanos capixabas acusam publicamente há anos: o Espírito Santo é um Estado racista, que adota práticas institucionais fundadas no preconceito contra negros e brancos pobres (..."tratados como pretos").
\end{abstract}

As argumentações sobre o preconceito e racismo no Brasil contribuem para avaliação do fato ocorrido no dia 30 de novembro de 2013 em um shopping de Vitória como reflexo direto da relação da negativa da prática do racismo no Brasil e seus efeitos na contemporaneidade, contudo, há um fator que necessariamente deve ser apresentado: o papel do Estado nesta prática. Pois como já demonstrado, as cenas protagonizadas no evento em questão estão diretamente ligadas com a ação institucional da Polícia Militar, com completo respaldo da Secretaria de Segurança Pública e Defesa Social do estado do Espírito Santo. 


\section{CORPOS NEGROS EXPOSTOS EM UMA PRAÇA DE ALIMENTAÇÃO DE UM SHOPPING}

Assim, a seletividade de suspeitos é uma realidade, visto que estudos demonstram que nos países de terceiro mundo a racialização é fruto de um processo que dispensa o uso da palavra raça à medida que os negros são geralmente associados à pobreza e ao protagonismo de diversas formas de violência, como o tráfico de drogas, inclusive com o pensamento de exclusão territorial da população negra. (GOLDBERG, 2000, apud RONDON FILHO, 2013).

Pautando os relatos acima é importante que a conduta dos cidadãos e cidadãs comuns que estavam presentes no dia do evento, ou seja, os indivíduos que não pertenciam ao grupo dos policiais nem tampouco ao grupo dos jovens concebidos como invasores, também devem ser objeto de estudo, pois suas ações e reações os tornaram agentes ativos durante toda a ocorrência do episódio.

\section{ESTE ESPAÇO NÃO É SEU}

As narrativas apresentadas permitem compreender que houve no dia 30 de novembro de 2013, em um shopping da capital do estado do Espírito Santo um acontecimento que merece uma atenção especial da sociedade, pois pode contribuir para demonstrar determinada configuração social que permeia as relações sociais cotidianas de poder, não apenas na cidade de Vitória, que foi o palco do acontecimento em questão, mas também em todo território brasileiro. Configurações que podem ser analisadas considerando as reflexões sociológicas apresentadas por Norbert Elias e John I. Scotson na obra Os estabelecidos e os outsiders: Sociologia das relações de poder a partir de uma pequena comunidade, editada pela primeira vez em $1965^{12}$.

Elias e Scotson não objetivam em sua obra da diferenciação de grupos pautados na ocorrência de racismo, visto que seu objeto de estudo - a vila de Winston Parva, não havia diferenças étnicas entre os moradores representantes dos grupos denominados Estabelecidos e Outsiders, nem tampouco de uma diferenciação pautada nas condições econômicas de seus moradores, pois estas eram muito similares, mas sim uma configuração social que permitia uma divisão regulada em um sentimento de pertencimento a um determinado espaço físico, um grupo social com qualidades superiores dentro de uma sociedade, por razões subjetivas, mas que impedia objetivamente a aproximação dos grupos que eram figurados como distintos.

\footnotetext{
A descrição de uma comunidade da periferia urbana apresentada neste livro mostra uma clara divisão, em seu interior, entre um grupo estabelecido desde longa data e um grupo mais novo de residentes, cujos moradores eram tratados pelos primeiros como outsiders. 0 grupo estabelecido cerrava fileiras contra eles e os estigmatizava, de maneira geral, como pessoas de menor valor humano. Considerava-se que Ihes faltava a virtude humana superior - o carisma grupal distintivo - que o grupo dominante atribuía a si mesmo. (ELIAS; SCOTSON, 2000, p. 19).
}

A ideia de "[...] se sentir superior por fazer parte de um espaço há mais tempo, ou de um determinado grupo social" (ELIAS; SCOTSON, 2000, p. 19) pode ser caracterizada como um ponto de 
afirmação que no evento ocorrido no dia 30 de novembro de 2013 em um shopping de Vitória, imperou a lógica de figuração social semelhante à encontrada entre os Estabelecidos e os Outsiders de Winston Parva, pois ficou evidenciado, como veremos adiante, que os conflitos gerados no interior do shopping, também se pautaram em uma reação de um grupo que se sentia apto a frequentar um determinado local público, ou seja, se sentia pertencente àquele ambiente, em detrimento de outro grupo que foi percebido como estranho àquele ambiente, reconhecidos pelo grupo que se sentia próprio ao ambiente em discussão, como incapazes de seguirem as regras pré-estabelecidas de convivência naquele determinado espaço, fazendo com que a presença daqueles observados como estranhos, fosse 0 suficiente para causar medo e pânico, originado em um imaginário de preconceitos.

Mas o caso ocorrido no shopping evidencia alguns motivos que levaram o grupo que se sentia pertencente a se julgar diferente o segundo grupo, compreendido pelo primeiro, como não pertencente. Um dos motivos é o reconhecimento que a área geográfica onde se encontra o shopping é uma região da cidade que abriga, como residentes, pessoas com um elevado poder econômico e, que os jovens que empreenderam fuga para dentro do shopping, eram moradores de periferia, visivelmente reconhecidos por seus trajes e cor de pele, que destoam em sua maioria da população de pele branca residente na referida área nobre.

Semelhante à comunidade de Winston Parva onde o grupo dos Estabelecidos negava-se a manter outro tipo de relação social com os Outsiders que ultrapassasse as questões relacionadas ao trabalho, à população que historicamente é frequentadora do shopping onde ocorreu o evento e residente nas áreas mais nobres da cidade, negou-se em escala expressiva a dividir o mesmo espaço com uma população formada por moradores das periferias da cidade, na sua maioria jovens, pois não houve reconhecimento por parte da população que se via como pertencente, ou seja, com o direito a frequentar o shopping, de que os jovens e adolescentes residentes na periferia, ou os nãos pertencentes, pudessem ocupar aquele local, em uma condição diferente a de trabalhadores, com a função de garantir o atendimento das necessidades do grupo pertencente.

Basta falar com as pessoas de lá para deparar com o fato que os moradores de uma área,
na qual vivia as "famílias antigas" consideravam-se humanamente superiores aos residentes
da parte vizinha da comunidade, de formação mais recente. Recusam-se a manter qualquer
contato social com eles, exceto o exigido por suas atividades profissionais; juntavam-nos
todos num mesmo saco, como pessoas de espécie inferior. (ELIAS; SCOTSON, 2000, p. 20).

A existência de um sentimento de superioridade do grupo que se reconhece com 0 pertencente, no caso específico o grupo social reconhecido como os frequentadores naturais do shopping na condição de clientes, em relação ao grupo socialmente reconhecido como não pertencente ao espaço comercial na condição de cliente é um modelo de configuração social preconizado por Elias e Scotson (2000, p. 19) ao afirmarem que "Vez por outra, podemos observar que os membros dos 


\title{
CORPOS NEGROS EXPOSTOS EM UMA PRAÇA DE ALIMENTAÇÃO DE UM SHOPPING
}

grupos mais poderosos que outros grupos interdependentes se pensam a si mesmos (se autorepresentam) como humanamente superiores".

Uma das condicionantes que Elias e Scotson apresentam para que este tipo de auto representação de superioridade se manifeste e a consequente estigmatização do outro grupo como inferior, é a condição de maior poder social de um grupo em relação ao outro.

\begin{abstract}
A peça central dessa figuração é um equilibrio instável de poder, com as tensões que lhe são inerentes. Essa é também a precondição decisiva de qualquer estigmatização eficaz de um grupo outsider por um grupo estabelecido. Um grupo só pode estigmatizar outro com eficácia quando está bem instalado em posições de poder das quais o grupo estigmatizado é excluído. Enquanto isso acontece, o estigma de desonra coletiva imputado aos outsiders pode fazer-se prevalecer. (ELIAS; SCOTSON, 2000, p. 23).
\end{abstract}

A reação da maioria das pessoas que se encontravam no shopping que se consideravam parte do grupo de pertencentes, em desenvolverem uma ação coletiva de rechaçamento da presença do grupo compreendido com não pertencente é explicável, visto que pode ser considerada uma ação de preservação de uma suposta posição social já adquirida, um temor em ser julgado por aqueles considerados seus iguais, pois qualquer atitude diferenciada daquela compreendida como natural pelo grupo de pertencentes, poderia colocar em questão a posição social do indivíduo no seu grupo social, pois a manutenção da coesão entre os indivíduos é um instrumento de garantia da conservação de poder do grupo, mesmo que subjetivo.

Entre os já estabelecidos, cerrar fileiras certamente tem a função social de preservar a superioridade de poder do grupo. Ao mesmo tempo, a evitação de qualquer contato social mais estreito com os membros do grupo outsiders tem todas as características emocionais do que, num outro contexto, aprendeu-se a chamar de "medo da poluição". Como os outsiders são dados como anômicos, o contato íntimo com eles faz pairar sobre os membros do grupo estabelecido a ameaça de "infecção anômica": estes membros podem ficar sobre suspeita de estarem rompendo as normas e tabus e seu grupo; a rigor, estariam rompendo essas normas pela simples associação com membros do grupo outsiders. Assim, o contato com os outsiders ameaça o "inserido" de ter seu status rebaixado dentro do grupo estabelecido. Ele pode perder consideração destes - talvez não mais pareça compartilhar do valor humano superior que os estabelecidos atribuem a si mesmo. (ELIAS; SCOTSON, 2000, p. 26).

As correlações realizadas entre o episódio ocorrido no shopping com as configurações de poder apresentadas na obra de Elias e Scotson abrem caminho para que possa ser analisado o fato com uma visão crítica na existência de preconceito racial no Brasil, pois ao refletir sobre as raízes históricas do racismo é possível concluir que o preconceito de raça no país também está fortemente apoiado na desigualdade social e econômica de dois grupos distintos.

No Brasil, o preconceito racial foi construído a partir da interação entre dois grupos: uma classe política e economicamente dominante, com uma concepção de mundo considerada superior, que passou a dominar um outro grupo pela estrutura econômica baseada na escravidão; o grupo dos negros, que passou a ser considerado inferior, crença que levou a justificar a dominação sobre ele. À medida que o grupo dominado passa a compartilhar as mesmas crenças sobre si mesmo e a submeter-se ao controle imposto, o processo se legitima (FRANKLIN; CAMARGO, 2001, p.79). 
O reflexo da formação histórica brasileira que favorece a existência de um racismo silencioso contra a população negra está presente em nosso cotidiano, que apresenta com um forte destaque a tentativa histórica de branqueamento da população brasileira, inclusive com a formulação de valores negativos atribuídos as características étnico- raciais. Condições que contribuem com a exclusão social das populações. Explicitados nas afirmativas em destaque.

No dia-a-dia das práticas sociais, tanto as pessoas que se consideram parte do 'outro grupo'
quanto o próprio afrodescendente, tendem a introjetar valores negativos associados às
características etno-raciais negras. Identidades assim constituídas mantêm a incapacidade
de desenvolver atitudes afirmativas relacionadas às especificidades raciais. Tais condições
constituem terreno fértil para a exclusão social desta grande parcela da população brasileira,
condição para um verdadeiro genocídio silencioso, gradual e lento. A experiência da
escravidão no Brasil transformou o africano em escravo; o escravo, em negro, e o negro,
numa pessoa que tende a desaparecer em nome da constituição de um povo cordial e
moreno. (FRANKLIN; CAMARGO, 2001, p.80).

A existência do racismo no Brasil, bem como a sua negativa são explicitados em pesquisas científicas sobre a temática. Em uma pesquisa de opinião realizada pela Fundação Perseu Abramo em 2003 demonstrou que 87\% dos entrevistados admitiram que há racismo no Brasil, mas somete $4 \%$ se reconhecem como racista. (SANTOS, 2005). Estes números permitem as seguintes percepções: nem todas as pessoas que cometem racismo estão conscientes de sua prática, pois este é sentido mais em quem é submetido ao racismo do quem o comete, bem como é possível concluir que 0 racismo é percebido sempre como uma prática do outro.

A desigualdade, a diferença e a discriminação racial no país, somente ficam evidenciadas em eventos como este ocorrido no shopping, pois quando os sentimentos de ódio, medo e repulsa são materializados em ações por parte de cidadãos, cidadãs e o próprio Estado, a negativa perde espaço perante um fato real, principalmente quando constatado, que mesmo com todas as imagens do evento publicadas nas redes sociais, a cobertura da imprensa, com riqueza de detalhes da ocorrência, por meio da divulgação de fotos, das opiniões das autoridades e testemunhas do evento, as autoridades locais insistiram na existência de normalidade na ação protagonizada pela polícia militar.

O fato somente se tornou uma peça alvo de investigação pela corregedoria da PM, por interferência da Secretaria de Políticas de Promoção da Igualdade Racial (SEPPIR), órgão do governo federal, que atendendo a denúncias diversas de organizações do Movimento Negro representou 0 governo do estado do Espírito Santo para que tomasse providências quanto à apuração do caso, contudo, a conclusão do inquérito foi que não teve racismo nem abuso dos policiais durante a operação, mas um fato curioso na metodologia de investigação foi o fato de nenhum dos jovens envolvidos terem sido ouvidos durante a investigação, pois as conclusões da peça de investigação foi baseada apenas nas informações fornecidas por lojistas e dos próprios policiais envolvidos, condição que causou revolta junto aos membros do O Fórum Estadual da Juventude Negra (Fejunes). 
O Fórum Estadual da Juventude Negra (Fejunes) divulgou nota de repúdio à Corregedoria da Polícia Militar pela publicação do inquérito policial que apurou o episódio ocorrido no Shopping Vitória, em 30 de dezembro de 2013, quando dezenas de jovens se abrigaram no centro comercial depois de um baile funk ao ar livre ter sido encerrado pela Polícia Militar, no "Encontro Do Amigo". A investigação concluiu que não teve racismo nem abuso dos policiais durante a operação. $O$ inquérito foi instaurado depois de representação da Ouvidoria da Secretaria de Políticas de Promoção da Igualdade Racial da Presidência da República (Seppir), que recebeu diversas denúncias de organizações do Movimento Negro. A entidade salienta que, durante todo o procedimento, só foram ouvidos policiais militares, lojistas e representantes do shopping. Os jovens abordados na ocorrência não foram ouvidos e não puderam relatar como foi a abordagem. Também não foram levadas em consideração, no inquérito, as imagens registradas durante 0 incidente por clientes e pelo próprio sistema de videomonitoramento do estabelecimento. (FRANCEZ, 2014, p. 1).

O caso do shopping é mais um episódio que ao mesmo tempo em que desnuda a prática do racismo no Brasil, coloca em evidência a força dos instrumentos conceituais, estruturais e conjunturais que impedem, a todo o tempo, que a temática seja concebida como uma questão de importância singular na sociedade.

Vencer a negativação do racismo no país e romper com a ilusão da chamada Democracia Racial é uma tarefa que merecerá muito esforço, visto que, em um caso como o narrado, em que os fatos puderam ser materializados em forma de imagens e disponibilizados para todo Globo terrestre e mesmo assim foram insuficientes para formar juízos de irregularidades junto às autoridades responsáveis pela investigação. Fica evidente que ainda impera no imaginário coletivo de parcela significativa da população, uma frase agressiva, subjugadora, estigmatizante, carregada de preconceito, apartamento racial, coercitiva e ideológica, mas que sempre fora apresentada como uma piada inocente: preto parado é suspeito, correndo é ladrão.

\section{CONCLUSÃO}

O fatídico dia 30 de novembro de 2013 não pode ser desconsiderado ou tratado com pouca importância na história do estado do Espirito Santo. A data vai ser lembrada, por muitos, como mais um episódio de discriminação e preconceito racial, pois setores da sociedade manterão, pautados nas análises do fatos, imagens e relatos de diversos atores, que os jovens envolvidos no episódio foram tratados como cidadãos sem direto pela Polícia Militar, mesmo depois de serem abordados, revistados e comprovado que não eram portadores de nenhum objeto ilícito, bem como não haviam cometido nenhum crime ou ato infracional que os colocassem em condições de ilegalidade.

As imagens de dezenas de jovens subjugados e expostos sem camisas, na praça de alimentação do shopping e obrigados a ficarem com as mão entrelaçadas na nuca, em condição semelhante a que são submetidas a população carcerária em momentos de revista policial nos presídios, e depois expulsos com violência, de um espaço de livre acesso público, sem motivos que justificasse, dentro da legalidade, a necessidade da ação policial, são instrumentos e argumentos 
maiores que discursos para manutenção da tese existência de preconceito. Ficando evidente também, que os aparatos do Estado, em especial os da segurança pública, podem sim, estarem sendo utilizados, ao longo da história, como instrumentos para manutenção de um apartamento social e racial no país.

O não reconhecimento, por parte dos organismos de segurança do estado do Espírito Santo, de que houve excessos e abusos na ação dos policias, extraídas das declarações públicas de um secretário de segurança pública estadual, que em momento algum admitiu ver qualquer anormalidade nos fatos, mesmo com as narrativas de testemunhas, as matérias exibidas na imprensa e as imagens diversas postadas nas redes sociais, bem como a necessidade de interferência externa para que uma investigação fosse instaurada, deixa evidente que a negativa do racismo, além de refletir na contemporaneidade ainda é um fator de resistência na luta pela construção de um país onde a justiça e a igualdade de direitos imperem para todos os cidadãos e cidadãs, independente das diferenças sociais e, em especial, a cor da pele.

\section{REFERÊNCIAS}

ADORNO, S. Racismo, criminalidade violenta e justiça penal: réus brancos e negros em perspectiva comparativa. Revista Estudos Históricos, São Paulo, n. 18, p. 283-300, 1996.

BELCHIOR, D. Shopping Vitória: Corpos Negros no Lugar Errado. Carta Capital, São Paulo, 2013. Disponível em: http://www.cartacapital.com.br/. Acesso em: 23 abr. 2015.

BOSSATO, G. Pânico e correria em Shopping: Grupo que participava de festa atrás do Shopping Vitória entrou correndo no local após chegada da Polícia Militar. A Tribuna, Vitória, p. 14, 2013.

CARVALHO, E.; HEMERLY, D. Jovens dançam armados em festa: Segundo a polícia, jovens foram flagrados dançando com armas nas mãos durante festa em Vitória, Dois foram baleados. A Tribuna, Vitória, p. 11, 2013.

CERQUEIRA, D. R. C.; MOURA, R. L. de. Vidas Perdidas e Racismo no Brasil. Brasília, DF: IPEA, 2013. (Nota Técnica, n. 10). Disponível em: http://www.ipea.gov.br/portal/images/stories/PDFs/nota_tecnica/131119_notatecnicadiest10.pdf. Acesso em: 20 nov. 2014.

ELIAS, N.; SCOTSON, J. L. Os Estabelecidos e os Outsiders: sociologia das relações de poder a partir de uma pequena comunidade. Rio de Janeiro: Jorge Zahar Ed., 2000.

FOLHA VITÓRIA. Menores invadem shopping para fugir da polícia e provocam pânico em clientes. Folha Vitória, Vitória, 2013. Disponível em: http://www.folhavitoria.com.br/policia/noticia/2013/11/menores-invadem-shopping-para-fugir-da-policiae-provocam-panico-em-clientes.html>. Acesso em: 15 maio 2018.

FRANCEZ, L. Conselho Estadual de Direitos Humanos repudia ação policial no Shopping Vitória Século Diário, Vitória, p. 1, 2013. Disponível em:https://seculodiario.com.br/public/jornal/materia/conselho-estadual-de-direitos-humanos-repudia- 
acao-policial-no-shopping-vitoria-1. Acesso em: 1 dez. 2015.

FRANCEZ, L. Fejunes repudia resultado de inquérito que apurou conduta de PMs em shopping: a investigação concluiu que não houve racismo nem abuso na operação que expulsou um grupo de jovens que dava um "rolezinho" no shopping. Século Diário, Vitória, p. 1, 2014. Disponível em: https://seculodiario.com.br/public/jornal/materia/fejunes-repudia-resultado-de-inquerito-que-apurouconduta-de-pms-em-shopping-1. Acesso em: 1 abr. 2016.

FRANKLIN, R. F.; CAMARGO, A. C. A naturalização do preconceito na formação da identidade do afrodescendente. Eccos Revista Científica, São Paulo, v. 3, n. 1, p. 75-92, 2001.

HEMERLY, D. Festas clandestinas vão ser rastreadas: após a confusão envolvendo baile atrás de shopping, Prefeitura de Vitória anunciou que vai vigiar eventos nas redes sociais. A Tribuna, Vitória, $p$. 20, 2013.

MIRANDA, J. Correria e Perseguição Policial em Shopping: Jovens correram para o local, após abordagem em baile funk. A Gazeta, Vitória, 2 ed., p. 14, 01 dez. 2013a.

MIRANDA, J. Lojistas e funkeiros criticam ação da polícia em shopping: policiais teriam agredido menores; Associação de Funk diz que houve discriminação. A Gazeta, Vitória, p. 10, 2013b.

MOREIRA, A. O Arrastão do Preconceito. Século Diário, Vitória, p. 37, 2013. Disponivel em: http://seculodiario.com.br/14276/14/o-arrastao-do-preconceito-1. Acesso em: 22 abr. 2015.

NUCCI, G. de S. Código de Processo Penal Comentado. 6. ed. São Paulo: RT, 2007.

RIBEIRO, A. E. A Relação da Polícia Militar Paulista com a Comunidade Negra: a questão da abordagem policial. 2009. Dissertação (Mestrado em Metodologia de Ensino) - Programa de PósGraduação em Educação, Universidade Federal de São Carlos, São Carlos, 2009.

RONDON FILHO, E. B. Polícia e minorias: Estigmatização, desvio e discriminação. Dilemas: Revista de Estudos de Conflito e Controle Social, Rio de Janeiro, v. 6, n. 2, p. 269-293, 2013.

SANTOS, G. G. A cultura política da negação do racismo institucional. In SANTOS, G. G.; SILVA, M. P. Racismo no Brasil: percepções da discriminação e do preconceito racial no século XXI. São Paulo: Fundação Perseu Abramo, 2005.

SOUSA, C. Â. de M.; GOMES, C. A. da C. A juventude na ótica de policiais: a negação do direito na aparência. Linhas Críticas, Brasília, DF, v. 17, n. 34, p. 527-543, 2011.

\section{Notas}

1 Viralização é um termo que surgiu com o crescimento do número de usuários das redes sociais e blogs. A palavra é utilizada para designar os conteúdos que acabam ganhando repercussão (muitas vezes inesperada) na web. 0 termo é relacionado a doença, já que as pessoas chegam a compartilhar o conteúdo quase que inconscientemente, criando uma epidemia de internautas falando sobre o mesmo assunto.

2 A Pontifícia Universidade Católica de São Paulo (PUC-SP) é uma instituição de ensino superior privada e católica brasileira. É mantida pela Fundação São Paulo (FUNDASP), vinculada à Mitra Arquidiocesana da cidade de São Paulo. Possui reconhecimento nacional e internacional pelo seu ensino e tradição

${ }^{3}$ A Uneafro Brasil - União de Núcleos de Educação Popular para Negras/os e Classe Trabalhadora agrega militantes da causa negra, da luta anti-racista, da causa das mulheres, da diversidade sexual e do combate a todos os tipos de 
discriminação e preconceito; da causa da Educação Popular e Libertária, da disseminação do protagonismo comunitário e da luta contra a exploração econômica e a dominação política.

${ }^{4}$ Artefato pirotécnico feito com papel enrolado com pólvora em pó, tendo uma cabeça semelhante à de um palito de fósforo que é riscado e atirado longe, provocando pequena explosão.

5 O BME é uma unidade Especial/ Operacional da Polícia Militar do Espírito Santo utilizada em missões onde a tropa regulara não disponha de meios materiais e técnicos suficientes para tais ações. O BME pode ser empregado em todo 0 Estado do Espírito Santo como tropa reserva do Comando Geral em operações que transcendam a capacidade operativa do policiamento local.

${ }^{6}$ Os moradores e turistas de Vitória podem ligar para o telefone 190 (Ciodes) para acionar os agentes de trânsito e os agentes comunitários de segurança da Guarda Civil Municipal. Os agentes de trânsito devem ser acionados em situações envolvendo a organização do trânsito na cidade; acidentes; serviço de guincho; fiscalização de obras em via pública ou flagrantes de infração ao Código Brasileiro de Trânsito. Os agentes comunitários de segurança devem ser acionados em casos de dano ao patrimônio público, para denúncias de pequenos delitos ou de situações suspeitas em praças, escolas e parques municipais.

7 tubo de escape, ou escapamento, é um condutor que possibilita aos veículos automotores encaminhar os gases do resultado da combustão para fora do ambiente do motor.

8 O CEDH, foi criado pela Lei Estadual 5.165 publicada em 20 de dezembro de 1995. Formado por vinte e quatro (24) membros, entre titulares e suplentes, com composição de instituições governamentais e entidades da sociedade civil organizada. É incumbido de várias atribuições, tais como: elaboração de políticas públicas na área de Direitos Humanos; receber e encaminhar denúncias sobre violações de Direitos Humanos; criar colegiados municipais; fazer diligência e fiscalização em estabelecimentos penitenciários e fomentar a cultura dos Direitos Humanos na perspectiva de uma nova sociedade. O Conselho não possui nenhum vínculo hierárquico com o Governo do Estado, porém, é ligado à Secretaria de Justiça para fins administrativos e operacionais.

${ }^{9}$ Modalidade de assalto coletivo, praticado por um grupo numeroso, geralmente em ambiente urbano, que rouba as pessoas e os espaços por onde se desloca.

10 Abrangência da busca pessoal: envolve as roupas, o veículo os pertences móveis que esteja carregando (bolsas, mochilas, carteiras etc.), bem como o próprio corpo. Esta última hipótese deve ser tratada com especial zelo e cuidado, pois significa ato extremamente invasivo. Pode, no entanto, ser necessária a diligência, como tem ocorrido nos casos de tráfico de entorpecentes, quando os suspeitos carregam, entre as nádegas ou os seios, pequenos pacotes contendo drogas.

11 Art. 244. A busca pessoal independerá de mandado, no caso de prisão ou quando houver fundada suspeita de que a pessoa esteja na posse de arma proibida ou de objetos ou papéis que constituam corpo de delito, ou quando a medida for determinada no curso de busca domiciliar.

${ }^{12}$ As palavras establishment e established são utilizadas, em inglês, para determinar grupos e indivíduos que ocupam posição de prestígio e poder. Um establishment é um grupo que se autoperceben e que é reconhecido como uma boa sociedade, mais poderosa e melhor, uma identidade social construída a partir de uma combinação singular de tradição, autoridade ou influência: os established fundam seu poder no fato de serem um modelo moral para ou outros.

Na língua inglesa, o termo que completa a relação e outsiders, os não membros da boa sociedade, os que estão fora dela. Trata-se de um conjunto heterogêneo e difuso de pessoas unida por laços sociais menos intensos do que aqueles que unem os established. A identidade social destes últimos é a de um grupo. Eles possuem um substantivo abstrato que os define como um coletivo: são os establishments. Os outsiders, ao contrário, existem sempre no plural, não constituindo propriamente um grupo social. (ELIAS; SCOTSON, 2000, p. 7). 